\title{
Teorías y técnicas frente a los terremotos de Italia central, 2016-17
}

Claudio Varagnoli | Departamento de Arquitectura, Universidad de Chieti-Pescara

URL de la contribución <www.iaph.es/revistaph/index.php/revistaph/article/view/4118>

Los terremotos de L'Aquila del 6 de abril de 2009 y los más recientes de 2016-17 golpearon una misma área que comprende ciudades importantes para la historia del arte, como L'Aquila (2009), Amatrice, Norcia, Camerino (2016-2017), pero también pueblos de dimensiones menores, marginales y económicamente en decadencia. Se trata de poblaciones inferiores a los mil habitantes, muchas ni siquiera superan unos pocos cientos e incluso decenas de habitantes.

Todavía hoy, los pueblos de esta región parecen en situación de abandono debido a los problemas causados por los sismos, que aún persisten (septiembre 2017). Aunque es conveniente señalar que estas regiones sufrían ya un proceso de despoblación antes del terremoto. L'Aquila, por ejemplo, sobrevivía, con anterioridad a 2009, gracias al aporte de los estudiantes universitarios, que compensaban el desplazamiento de habitantes a otras ciudades.

El daño causado por la larga secuencia sísmica acaecida entre el 24 de agosto de 2016 y el 18 de enero de 2017 reveló la fragilidad inherente al patrimonio arquitectónico de una parte notable de Italia. El daño no solo se produjo en casos de reconstrucciones incompletas o mal ejecutadas, sino también en restauraciones llevadas a cabo adecuadamente. Un desastre natural, como este, supone un momento decisivo para la disciplina de la restauración, en cuanto que se evalúa la efectividad en el tiempo de las técnicas de consolidación empleadas.

La variedad de los daños sufridos y de los tipos de mampostería destruidos por los seísmos previos pusieron de relieve situaciones muy diferentes, ya visibles antes del colapso final que se produjo con el terremoto del 18 de

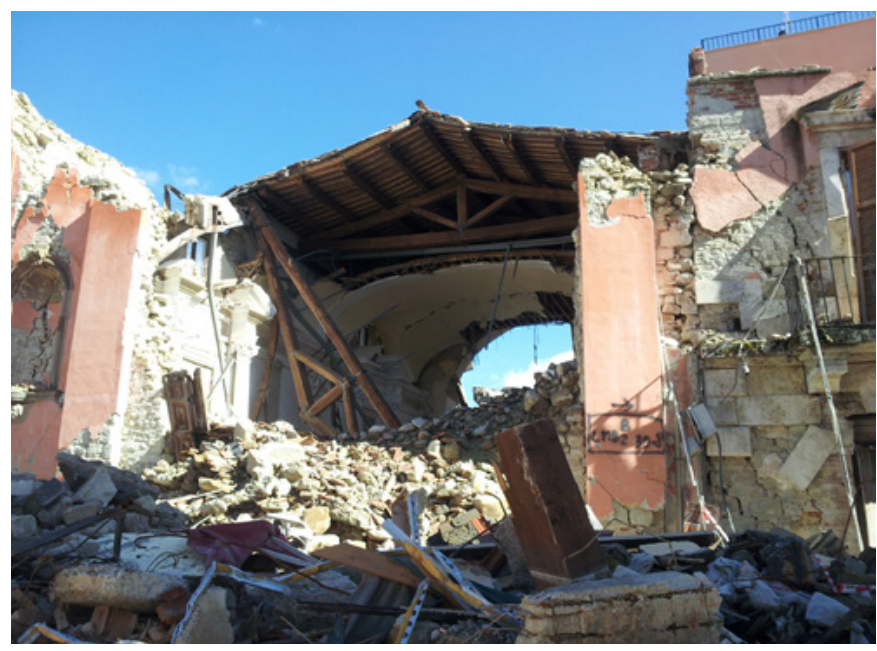

Terremotos de Italia central, 2016-17 | foto Claudio Varagnoli

enero de 2017. En el centro histórico de Amatrice, los muros estaban construidos habitualmente con fábricas donde los materiales pétreos, de piedras y guijarros, ocupaban menos de la mitad de su espesor. Como consecuencia, en la mayoría de los casos, no se logró una adecuada trabazón en la fábrica de mampostería, que sólo se consigue cuando se disponen mampuestos de tamaño suficiente para atravesar el grosor del muro, otorgando a la fábrica un comportamiento monolítico.

Además, las intervenciones realizadas durante el siglo XX fueron en muchos casos perjudiciales, como la remodelación de fachadas con sillares que no se traban con las fábricas preexistentes; además de las muchas chimeneas y, sin duda, las elevaciones, los tejados, las aberturas y los balcones en hormigón armado. Tampoco debemos olvidar la escasa resistencia de los morteros empleados: en algunos casos, especialmente en los pueblos cerca de Amatrice, se han encontrado morteros terrosos, que se desmoronan fácilmente bajo los dedos. 


\begin{abstract}
a debate Patrimonio, terrorismo y desastres naturales ¿Cómo prevenir y abordar los enormes daños al patrimonio cultural mundial?
\end{abstract}

| coordinan Francisco Javier López Morales, Francisco Vidargas

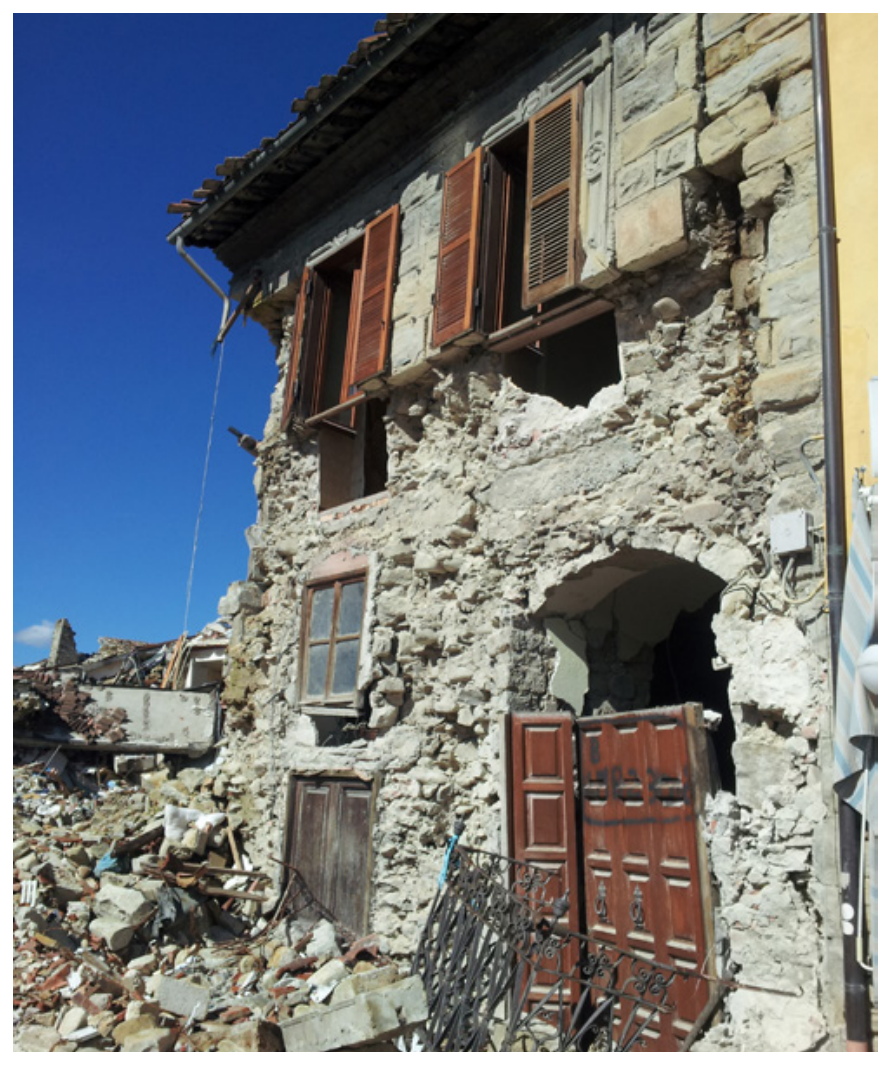

Terremotos de Italia central, 2016-17 | foto Claudio Varagnoli

El empleo de estos materiales es la causa del colapso de los diferentes elementos constructivos que o bien no contaban con elementos de conexión transversales, como tirantes de acero o madera, o que estos no resultaron eficaces ${ }^{1}$. La situación es diferente en L'Aquila, donde, después del terremoto de 2009, las medidas antisísmicas han reducido al menos los colapsos de determinados elementos constructivos.

También queremos hacer hincapié en que, en el caso de Amatrice, se trata de viviendas de uso casi exclusivo durante el verano, fruto del denominado "turismo de retorno" $y$, por lo tanto, no siempre tratadas con la atención que se presta a una residencia permanente. La situación en Norcia es diferente, donde las medidas antisísmicas, planificadas durante el siglo XIX o tras el terremoto de 1997, han reducido en gran parte el impacto de los sismos. Como siempre, las iglesias son una excep- ción, donde los complejos sistemas constructivos disminuyen la vulnerabilidad sísmica²

Los comentarios de periodistas y especialistas también cuestionan la supuesta sabiduría constructiva de los siglos pasados, y plantean si la experiencia repetida de terremotos en la zona no sirvió para enseñar a constructores y patrones. Si Amatrice y sus aldeas eran áreas sujetas a riesgo sísmico, ¿por qué los habitantes continuaron construyendo de una manera que no evitaba el peligro? ¿Es necesario registrar los errores del modo de construcción tradicional?

Quizás vale la pena recordar que el terremoto fue percibido, entre los campesinos de Italia central, como un evento sujeto a creencias religiosas. Por lo tanto, el terremoto se consideraba una especie de castigo o expiación debido al comportamiento inmoral de una comunidad. Esto queda reflejado, por ejemplo, en los informes elaborados después del terremoto de L'Aquila en 1703, que tuvo su momento más dramático el 2 de febrero, el día de la Purificación.

Increíblemente, las primeras medidas tomadas en el terremoto de 2016-17 fueron la exclusión injustificada de los representantes de la cultura de la conservación y la ausencia de las Soprintendenze, que normalmente cuidan al patrimonio artístico y arquitectónico de acuerdo con la legislación nacional. Parece que las necesidades de un patrimonio muy rico y diversificado, en una de las áreas más importantes de la cultura artística italiana, no está en el centro de las prioridades. Más bien, parece que estamos volviendo a la contraposición entre la seguridad y la conservación, con intervenciones drásticas como el traslado de aldeas enteras, sin prestar atención al futuro de las ruinas y la carga de conocimiento que transmiten. También reaviva la tendencia a devaluar la importancia de los tejidos históricos y sus conexiones con el territorio, a favor de un programa destinado únicamente a los "monumentos" individuales. Los trabajos de reconstrucción seguidos tras los eventos sísmicos de 2016-17 son un caso traumático, que la cultura italiana no está afrontando con la debida conciencia. La larga 
a debate Patrimonio, terrorismo y desastres naturales ¿Cómo prevenir y abordar los enormes daños al patrimonio cultural mundial?

| coordinan Francisco Javier López Morales, Francisco Vidargas

duración y las dificultades de las reconstrucciones explican la secuencia de abandonos y ruinas que salpican todo el centro y el sur de los Apeninos de Italia.

Esta situación arroja una sombra amenazante respecto del proceso de la reconstrucción: ¿por qué reconstruir edificios y centros históricos en los cuales no va a vivir nadie?, ¿por qué restaurar y consolidar un patrimonio habitable que tiene grandísimas limitaciones de uso, en términos de accesibilidad, instalaciones, localización, servicios y que, por esto ya había iniciado antes del terremoto un proceso de marginación y de abandono? Preguntas apoyadas por la misma población, que en más de una ocasión ha manifestado su desconfianza ante las viviendas con mampostería tradicional, prefiriendo nuevas edificaciones en hormigón armado.

\section{NOTAS}

1. Los esfuerzos a los que los muros de carga fueron sometidos, tanto axiales como cortantes, provocaron su deterioro estructural y material con pérdidas de la estabilidad o la aparición de otras patologías constructivas como desprendimientos, fisuras y grietas, entre otros.

2. Los diferentes elementos constructivos -muros, bóvedas, cubiertas inclinadas- se comportan de manera más solidaria y mejoran la estabilidad de los muros frente al sismo. 